www.jmscr.igmpublication.org

Impact Factor (SJIF): 6.379

Index Copernicus Value: 79.54

ISSN (e)-2347-176x ISSN (p) 2455-0450

crossrefDOI: https://dx.doi.org/10.18535/jmscr/v6i10.182

\title{
A Clinical Study of Thyroiditis and Its Correlation with TFT, USG, FNAC and Anti TPO Antibodies
}

\author{
Authors \\ Ravisankar $\mathbf{P}^{1}$, Shakthi Saravanan K V ${ }^{2}$, Anvar Ali A ${ }^{3}$, Vinodh Kannan $T^{4}$
}

\begin{abstract}
Aims and Objectives: To study a population of 50 people in a rural tertiary care hospital with goitre presenting in surgical opd, do a thorough clinical examination, Thyroid function test, ultrasonogram of neck, Fine needle aspiration cytology, anti thyroid peroxidise titres and correlate with incidence of thyroiditis and other causes of goitre
\end{abstract}

Materials and Method: 50 people attending surgical OPD in Rajah Muthaiah Medical college hospital presenting with goitre excluding those who are on previous management.

Results: It was found in the study that all patients of thyroiditis (hashimoto's) and grave's disease have increased titres of Anti TPO antibodies (thyroiditis >>grave's) and there was no correlation between thyroid function tests and ANTI TPO antibodies.

Conclusion: As such Anti TPO antibodies can be used a tool in diagnosing thyroiditis in thyroid swellings mimicking malignancy which may otherwise need surgery as thyroiditis responds well to medical management.

\section{Background}

Thyroid diseases are arguably among the most commonest endocrine diseases of the world and patient usually present to the OPD with a insidiously growing goitre. In the developing world iodine deficiency is considered as the most commonest cause of goitre however it is rapidly changing with better diagnostic procedures many more etiologies being identified biosynthetic defects, autoimmune diseases, neoplastic and nodular diseases being increasingly more common

\section{Introduction}

In a sample survey conducted from 325 districts all over India it was found that almost more than 75 million people suffer from goitre. of which colloid goitre from iodine deficiency remained commonest followed by autoimmune and malignant diseases being least common.

Thyroid function tests estimating TSH, free T3 and free $\mathrm{T} 4$ has remained of first line of investigation for goitre. TSH correlates with impact of thyroid harmone levels in the patient while free T4 level generally correlates with severity of harmone deficiency or excess

Anti Thyroid Peroxidase antibodies along with TSH-R antibodies and Thyroglobulin antibodies are widely useful in diagnosing Auto Immune Thyroid Diseases. However Anti TPO antibodies have higher affinity toward autoimmune thyroid diseases are secondary response to thyroid injury. They belong to IgG class. They are commonly 
affiliated with autoimmune thyroiditis (hashimoto's disease and atrophic thyroid failure). They're also seen in moderate titres in $50-90 \%$ of cases grave's diseases. They are still sporadically found in Nodular goitre and general population.

Ultrasonogram of neck is viewed as a extension of clinical examination and is very helpful in assessing a goitre in relation to size, extension, nodularity, vascularity and associated nodes which in turn gives clues of nature of the goitre either benign or malignancy. It also serves as tool for guided FNAC, such specimens increases the tissue yield and sensitivity.

Fine Needle Aspiration Cytolgy is a simple yet most powerful all tools in diagnosing thyroid swellings especially benign conditions. Yet care should be taken to avoid vascular injury and adequate tissue yield which is overcome by combining with ultrasonogram

\section{Aims and Objectives}

(1) To study a population of 50 people in a rural tertiary care hospital with goitre presenting in surgical opd

(2) To do thorough clinical examination, Thyroid function test, ultrasonogram of neck, Fine needle aspiration cytology, anti thyroid peroxidise titres and correlate with incidence of thyroiditis and other causes of goitre.

\section{Materials and Methods}

50 Patients attending the surgical OPD at RMMCH with goitre between 2016 and 2018.

\section{Inclusion Criteria}

New patients above 10 years of age presenting to surgery OPD with goitre.

\section{Exclusion Criteria}

Previously diagnosed thyroid swellings on medical or surgical management.

\section{Discussion}

Thyroiditis has remained a second most common individual etiology for goitre which may mimic malignancy. Routine evaluation of goitre at $\mathrm{RMMCH}$ a rural tertiary care hospital includes clinical examination, USG, TFT and FNAC and doesn't include anti TPO antibodies. Anti TPO antibodies serves as very reliable indicator of Autoimmune thyroiditis which may mimic malignancy. Here 50 individuals who presented with goitre are investigated, various etiologies identified, distribution and correlation between etiologies and investigations are charted.

Out of 50 patients 38 are females and 12 are female showing more female preponderance $4^{\text {th }}$ and $5^{\text {th }}$ decade are more affected with females affected a decade earlier than males

In our study $40 \%$ of population was in euthyroid state, $28 \%$ was in hypothyroid state and $22 \%$ was in hyperthyroid state.

\section{Anti TPO Titer}

\begin{tabular}{|l|c|c|c|c|c|c|}
\hline \multirow{2}{*}{$\begin{array}{l}\text { Titre } \\
\text { IU/ml) }\end{array}$} & \multirow{2}{*}{$\mathbf{0 - 5 . 6 1}$} & \multicolumn{2}{|c|}{ Total } & \multicolumn{2}{c|}{ Males } & \multicolumn{2}{c|}{ Females } \\
\cline { 2 - 7 } & $\begin{array}{c}\text { No. of. } \\
\text { patients }\end{array}$ & Percentage & $\begin{array}{c}\text { No. of. } \\
\text { patients }\end{array}$ & Percentage & $\begin{array}{c}\text { No of } \\
\text { patients }\end{array}$ & Percentage \\
\hline Normal & 24 & 48 & 4 & 8 & 20 & 40 \\
\hline Elevated & 26 & 52 & 8 & 16 & 18 & 36 \\
\hline
\end{tabular}

Anti TPO titer was found to be elevated in $52 \%$ of study population and normal in $48 \%$ of study population. $26 \%$ of our study population have titers of more than $1000 \mathrm{IU} / \mathrm{ml}$. All of which were cases of autoimmune thyroiditis.
FNAC showed most of the study population had colloid goiter which accounted for $30 \%$ followed by Hashimoto's thyroiditis contributing $28 \%$.

USG showed features of colloid goiter in majority of patients accounting 29 (58\%), followed by thyoiditis accounting 10 (20\%). 
Final Diagnosis

\begin{tabular}{|l|c|c|}
\hline Diagnosis & No. of. patients & Percentage \\
\hline Colloid goiter in euthyroid state & 7 & 14 \\
\hline Colloid goiter in hypothyroid state & 5 & 10 \\
\hline Colloid goiter in hyperthyroid state & 3 & 6 \\
\hline Colloid goiter in subclinical hypothyroid state & 1 & 2 \\
\hline Hashimoto's thyroiditis in euthyroid state & 4 & 8 \\
\hline Hashimoto's thyroiditis in hypothyroid state & 7 & 14 \\
\hline Hashimoto's thyroiditis in hyperthyroid state & 2 & 4 \\
\hline Hashimoto's thyroiditis in subclinical hypothyroid state & 1 & 2 \\
\hline Solitary nodule in euthyroid state & 2 & 4 \\
\hline Multi nodular goiter in euthyroid state & 6 & 12 \\
\hline Multi nodular goiter in hypothyroid state & 2 & 4 \\
\hline Multi nodular goiter in hyperthyroid state & 3 & 6 \\
\hline Multi nodular goiter in subclinical hypothyroid state & 1 & 2 \\
\hline Grave's disease & 3 & 6 \\
\hline Papillary carcinoma in subclinical hypothyroidism & 2 & 4 \\
\hline Follicular neoplasm in euthyroid state & 1 & 2 \\
\hline
\end{tabular}

\section{Conclusion}

As such Anti TPO antibodies can be used a tool in diagnosing thyroiditis in thyroid swellings mimicking malignancy which may otherwise need surgery as thyroiditis responds well to medical management.

\section{References}

1. Bailey and Love's Short Practice of surgery.editors Williams, O'Connor and McCaskie. $27^{\text {th }}$ edn.CRC press 2018. chapter 50.

2. Sabiston Textbook of Surgery. $20^{\text {th }}$ edn .editors Townsend. Elsiever 2016. chapter 38. 